\title{
Timm Kunstreich: por uma teoria crítica de Serviço Social
}

\section{Timm Kunstreich: a critical social service theory}

Tuto Beat Wehrle*

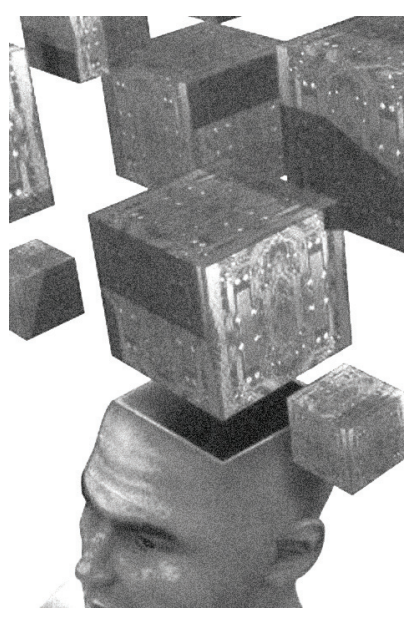

Resumo: O presente artigo faz uma reflexão quanto às tendências hegemônicas de reconfiguração das políticas sociais e da assistência social nos Estados de bem-estar europeus. Introduz, enquanto tendência contracorrente, o pensamento do assistente social alemão Timm Kunstreich, que busca viver, na teoria e na prática, um jeito crítico de exercício da profissão.

Palavras-chaves: Estado de bem-estar. Políticas sociais. Teoria crítica de Serviço Social.

\begin{abstract}
This article discusses the hegemony tendencies of the reconfiguration of social policies and social assistance in the European welfare states It introduces, as a countercurrent trend, the thought of the German social worker Timm Kunstreich, who tries to do his job as a social worker critically, both in its theoretical and practical aspects.
\end{abstract}

Keywords: State of well-being. Social policy. Critical theory of social service.

* Diretor da E-Changer - Fribourg, Suíça, organização suíça da cooperação internacional solidária; mestrando em Serviço Social na Pontifícia Universidade Católica de São Paulo — São Paulo, Brasil. E-mail: beat-tuto@uol.com.br. 


\section{Introdução}

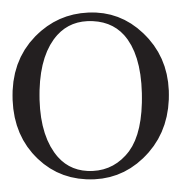

presente trabalho se propõe a apresentar o assistente social alemão Timm Kunstreich e contextualizar suas reflexões em torno de uma teoria crítica de Serviço Social. Kunstreich flutua com suas análises críticas e suas posturas emancipatórias feito ilha isolada na paisagem hegemônica da regulação liberal-conservadora da produção de bem-estar e em meio aos milhares de profissionais do Serviço Social a ela adaptados.

$\mathrm{Na}$ primeira parte, o presente trabalho analisa o contexto dos Estados de bem-estar e as transições percorridas nas décadas recentes. Na segunda parte, apresenta Timm Kunstreich e tenta reconstruir um breve perfil de seu pensamento.

\section{Os Estados de bem-estar e suas transições recentes}

Ao longo do século XX e, sobretudo, depois da Segunda Guerra Mundial, os países industrializados centrais, isto é, os países da Europa continental, os países escandinavos e a família de países anglo-saxões (Estados Unidos, Inglaterra, Austrália e Nova Zelândia) desenvolvem uma configuração específica de sistemas de proteção social. Este modelo conhecido como welfare reconhece direitos sociais de forma ampla e transforma a natureza política das relações entre Estado e sociedade. Conforme o sociólogo português Boaventura de Sousa Santos, o modelo do welfare se constrói a partir do regime fordista de produção que assegura uma partilha dos ganhos da produtividade capitalista por meio do aumento dos salários diretos e pela expansão de salários indiretos, "ou seja, os benefícios sociais em que se traduz a cidadania social e, em última instância" (Sousa Santos, 2002, p. 213-214), o welfare enquanto regime capitalista de bem-estar.

O processo de transnacionalização da produção e a internacionalização dos mercados que se consolida no último quartil do século XX provoca a crise de rentabilidade do capital e, por conseguinte, a crise de regulação nacional de produção de bem-estar que tem o Estado nacional como lócus político de regulação. Esse processo aprofunda-se na atualidade por um processo de financeirização, ou seja, pelo protagonismo do capital financeiro no comando do processo de acumulação no contexto da mundialização da economia (Iamamoto, 2007, p. 106-107). Os mercados financeiros e o grande capital produtivo buscam reverter a crise da rentabilidade do capital e capturam o Estado que reconfigura suas políticas a partir das exigências do mercado (Idem, p. 124). 
Evidentemente, essas determinações históricas redimensionam a questão social enquanto expressão sempre conjuntural e, portanto, multifacetária decorrente das contradições e antagonismos do regime capitalista. Mas, segundo a cientista social brasileira Marilda Villela Iamamoto, "a mundialização não suprime as funções do Estado de reproduzir os interesses institucionalizados entre as classes e grupos sociais, mas modifica as condições de seu exercício". O sociólogo inglês Bob Jessop interpreta a reconfiguração das políticas sociais no contexto dos Estados de bem-estar como transformação fundamental dos regimes de welfare e interpreta esse processo como "continuidade da acumulação do capital nas novas condições da economia global" (Jessop, 1986, p. 4; tradução nossa) e como passagem do "Estado nacional de bem-estar com perfil à la Keynes para o Estado pós-nacional de workfare à la Schumpeter" (Idem, p. 6). O sociólogo suíço Kurt Wyss verifica uma transição do welfare capitalismo para o workfare capitalismo, ou seja, a passagem para uma forma de regulação do bem-estar descentrada da produção de bem-estar e centrada na inserção dos usuários das políticas sociais no mercado de trabalho (Wyss, 2007). Para Wyss, a reconfiguração do welfare na perspectiva do workfare não se processa necessariamente por meio do desmonte de sistemas de proteção social. No entanto, ela altera a regulação da produção de bem-estar transformando, por exemplo, a assistência social em instrumento de controle social a serviço do capitalismo globalizado.

O workfare capitalismo pode ser descrito pelo tripé de ativação, trabalho e integração. Ele perverte o discurso proativo em absolutização da ativação que sempre pressupõe sujeitos sociais passivos, inertes e incapazes. Além disso, instrumentaliza o discurso do empoderamento (empowerment) que originalmente se identifica com uma prática emancipatória de Serviço Social. Se o empowerment busca a emergência de sujeitos sociais organizados e mobilizados no sentido de pautar a efetivação de seus direitos sociais de cidadania, o empowerment abraçado pelo modelo da ativação não empodera sujeitos individuais e coletivos dentro do contexto das condições de reprodução das relações sociais, mas se propõe a capacitar sujeitos passivos para que sejam empreendedores individuais capazes de garantir com autorresponsabilidade a sua existência material sem depender do Estado de bem-estar.

Bem-estar, neste contexto, se transfigura em capacitação para o trabalho. Por conseguinte, integração não significa outra coisa que inserção no mercado de trabalho. Não importa como: quem é ativo também tem que ser flexível. Assim, a integração discursivamente afirmada não é nada mais que a adaptação a uma vida na precariedade invisibilizada e a submissão a condições exploradoras, muitas vezes ilegais de trabalho. Quem não se integra, isto é, quem não se submete aos 
trabalhos obrigatórios é caracterizado como indisposto para o trabalho e como resistente à integração. Em consequência, sofrerá cortes dos benefícios sociais. Portanto, a reconfiguração do welfare na perspectiva do workfare por meio de políticas de assistência social que priorizam ativação, trabalho e integração, é mais sutil que o simples desmonte de sistemas de proteção social. O workfare freia, trunca e aborta processos de emancipação social e reedita mecanismos tradicionais de tutela autoritária.

Entrevista realizada (no contexto de elaboração da dissertação de mestrado para o Programa de Estudos Pós-Graduados em Serviço Social da Pontifícia Universidade Católica de São Paulo) com uma assistente social suíça traça com linhas claras a realidade atual nos centros de assistência social suíços.

A maior parte das pessoas que eu encontro em meu trabalho se queixa do tratamento recebido nos centros de assistência social. Sobretudo alegam que não se sentem respeitadas e não são levadas a sério. Penso que os centros de assistência social se transformam cada vez mais em um guichê da assistência. Nada diferente do guichê no banco. [...] Até mesmo o vidro separador não falta. E esse vidro é símbolo de outros vidros invisíveis que se fazem presentes e que aguçam a separação. As pessoas sentem isso. E tudo é feito para conservar esse vidro. Certamente isso não ocorre de forma consciente. [...] Mas é evidente que isso mostra uma grande insegurança, até mesmo um medo do outro que se encontra em outra situação de vida. Uma insegurança também quanto à própria função. Como o outro se relaciona comigo se tenho o poder de decidir pelo aumento ou pela redução de seu benefício? É claro que o fato de poder entrincheirar-se atrás de um vidro protetor ajuda. [...] Mas na situação atual desses centros de assistência social não há outra forma possível. Pois cada assistente social precisa dar conta de oitenta a cem casos. Nos centros de assistência social isso é absolutamente normal. Cada minuto conta. Pior que no médico. O que você não pode produzir nestes poucos minutos, simplesmente inexiste. (Wehrle, 2011, p. 35-36; tradução nossa)

O raciocínio de um usuário da assistente social entrevistado no mesmo contexto confirma a transição sistematizada por Wyss e mostra que a nova forma de regulação da produção de bem-estar não interfere apenas na vida do usuário da assistência social, mas reconfigura também as condições do exercício da profissão.

Os funcionários da máquina também trabalham sob pressão. Eles têm a obrigação de alcançar metas e resultados. Eles têm que te fazer desaparecer das estatísticas de todo jeito. Senão eles correm o risco de sentar-se na mesma cadeira que nem você. O sistema é perverso, eu diria antissocial. Os assistentes sociais [...] não dispõem das soluções para te ajudar. O problema está mais embaixo. Você não passa de um número 
de um caso no contexto de uma problemática global dirigida pelo capitalismo neoliberal. Você é inútil, fora de propósito, você incomoda. As pessoas te escutam, mas não te entendem. Eles não conseguem reduzir tua angústia, eles a aumentam. [...] Para mim, não tem jeito. A assistência social faz o que ela pode com os meios que ela tem à disposição. (Idem, p. 41-43)

Proliferam, nesses tempos, concepções metodológicas de Serviço Social que têm a pretensão de oferecer aos assistentes sociais as receitas perfeitas para alcançar a gestão do impossível. Muitas vezes, o Serviço Social degrada em caixa de ferramentas de tecnologias sociais. Na participação em diferentes módulos do curso de mestrado em Serviço Social, realizado de forma interinstitucional pelas Faculdades de Serviço Social das Universidades de Ciências Aplicadas de Berna, Zurique, Lucerna e St. Gallen, tive oportunidade de conhecer e aprofundar algumas.

Dentro do tradicional tripé “caso, grupo e comunidade”, há uma priorização sistemática pelo nível individual. A perspectiva metodológica supostamente inovadora do case management (acompanhamento de casos em base de práticas de gestão empresarial), por exemplo, se propõe a modernizar o acompanhamento tradicional do caso individual (social case work). No entanto, a proposta de fases da intervenção (assessment, service planing, intervention, monitoring) reedita com discurso supostamente modernizado o modelo tradicional-clínico de anamnese, diagnóstico, tratamento e avaliação.

Outro exemplo é a "metodologia da regulação socioecológica de serviços sociais" (sozialökologische Steuerung Sozialer Dienste). Ela busca conciliar os recursos e os obstáculos da pessoa (por isso "social") com os recursos e os obstáculos do meio ambiente (por isso "ecológico"). A pessoa não é considerada como ator social mediado pelas condições sociais, mas como ente individual com suas características de saúde, psicológicas e sociais enquanto ser mergulhado em um ambiente marcado por questões políticas, sociológicas etc. A dita "metodologia da regulação socioecológica" busca fortalecer a capacidade adaptativa da pessoa a um meio ambiente em processo de mudança e não enxerga a pessoa como ser social que intervém de forma individual e coletiva na produção e na reprodução da realidade social, mas que se submete e se adapta a uma realidade em processo de mudança.

Outras estratégias se propõem a facilitar a convivência com o número alto de casos acompanhados por assistente social (Fallsteuerung). O último levantamento científico desse número nos centros públicos de assistência social da Suíça data de 1998 e aponta para uma média de noventa casos (Kobel, 2009). A assistente social entrevistada faz referência a uma média similar. No entanto, a falta de levantamento científico atualizado leva à desconfiança que o número médio deve ter aumen- 
tado significativamente nos anos passados. Quando no módulo referido do curso de mestrado em Serviço Social o professor dirigiu a pergunta aos estudantes quanto a propostas de procedimentos frente à alta incidência de casos a serem acompanhados, respondi que os assistentes sociais deveriam entrar em greve para lutar por condições dignas de trabalho e pelas condições necessárias para um trabalho de qualidade. O professor parou, abriu-se aquele buraco de silêncio, como se eu tivesse dito algo que fora de total incompreensão. Depois de alguns longos momentos de interrupção da sequência de exposição, o professor retomou seu raciocínio como se nada tivesse sido dito. De fato, o conteúdo apresentado não questionou as condições de funcionamento da política de assistência social, mas se propôs a capacitar os estudantes por meio de metodologias de facilitação da gestão de um número alto de casos a serem acompanhados, isto é, a adaptação a uma realidade analisada como supostamente dada de forma inexorável.

\section{Timm Kunstreich: 0 pensamento de um assistente social destoante}

Sem dúvida, dentro do contexto atual de regulação do bem-estar, a perspectiva do workfare é hegemônica. Ela se torna visível e palpável na configuração da política de assistência social, mas se manifesta também como a perspectiva predominante no exercício da profissão, bem como nos espaços de formação da metodologia e da prática da profissão. Nenhuma hegemonia, no entanto, é absoluta. E onde há mar tem ilhas. Uma ilha interessante no mar sem fim do workfare capitalismo é o assistente social alemão Timm Kunstreich.

Inicialmente, Kunstreich estudou sociologia e economia política, mas complementou sua formação acadêmica com o estudo da pedagogia social (Sozialpädagogik), matéria inexistente no Brasil e cujo conteúdo é incorporado no Serviço Social. Trabalhou muitos anos na formação contínua de profissionais de Serviço Social e assumiu em 1992 uma docência na faculdade de Serviço Social da fundação denominada "Das Rauhe Haus" (A casa áspera).

A fundação foi constituída em 1832 e herdou seu nome da fazenda rural anteriormente existente no lugar, poucos quilômetros distantes dos muros da cidade de Hamburgo, Norte da Alemanha. A entidade foi em sua origem uma instituição de acolhida e de acompanhamento de crianças e de jovens, constituída e dirigida pela Igreja protestante. A primeira iniciativa de formação profissional da fundação oferecia um curso de teologia pastoral e, apenas mais tarde, transformou-se em faculdade de Serviço Social. Vários expoentes da fundação assumiram no período nazista posições publicamente contrárias ao regime. A instituição foi expropriada 
pelo governo nazista e totalmente destruída nos bombardeios aliados da cidade de Hamburgo de 1943. Em 1957, a nova faculdade foi inaugurada. Até hoje a fundação "Das Rauhe Haus" mantém serviços assistenciais e a faculdade de Serviço Social. Timm Kunstreich exerceu sua docência de 1992 até 2009, quando se tornou professor emérito. Ele é cofundador da revista especializada de Serviço Social Widersprüche (Contradições), com claro perfil marxista.

Os aspectos destacados no breve perfil teórico de Timm Kunstreich seguem a lógica do cientista social alemão Michael May, que sistematizou os principais "pontos cristalizadores da consolidação teórica profissional do Serviço Social" (May, 2008, p. 233; tradução nossa). May destaca que o Serviço Social não dispõe de uma grande teoria fundamental, mas é marcado por uma compreensão teórica aberta que acolhe distintos estilos de pensar e concepções diversas do Serviço Social. Para May, "o valor de uso de uma teoria está em sua capacidade de produzir conexões" (Idem, p. 39). E para corresponder a essa pretensão, uma produção teórica de Serviço Social precisa pronunciar-se quanto ao seu caráter científico, ao seu objeto, à relação entre teoria e prática, seus pressupostos sociais, seus usuários(as), suas instituições, a ação profissional e, finalmente, seus valores subjacentes.

Quanto ao caráter científico, as reflexões e análises de Timm Kunstreich se constituem a partir de uma perspectiva crítica e materialista. Para ele, a instância última de construção de história é a produção e a reprodução da vida real. Os seres humanos são os produtores do conjunto de suas formas históricas de vida. Eles não são objetos coisificados, mas constituem sujeitos que agem e intervêm de forma ativa. O projeto da perspectiva crítico-materialista é a superação da não identidade de sujeitos históricos ativos produzida pelo modo capitalista de produção de relações sociais. Para Kunstreich, os sujeitos e suas relações sociais são essencialmente relacionais. Os sujeitos que se caracterizam sempre e fundamentalmente pelo seu ser social constituem campos de forças e de conflitos por meio de sua prática cooperativa. Esses campos são descritos por Kunstreich como socialidades. O espaço social, portanto, se compõe pela multiplicidade infinita de relações em e entre as referidas socialidades. O social é, por conseguinte, "o tecido atual de cooperação entre seres humanos que cotidianamente continua a ser produzido e, assim, reproduz a sociedade em processo contínuo" (Kunstreich, 2006, p. 12; tradução nossa).

Do ponto de vista dos pressupostos sociais, Kunstreich chama a atenção para o fato de que as condições diversas da produção das relações sociais são condicionadas pelo modo desigual de acesso aos meios de produção das relações sociais. A razão de ser das situações específicas de vida dos(as) usuários(as) do Serviço Social decorre "de sua situação social enquanto trabalhadores assalariados sem ou com pouca qualificação profissional" (May, 2009, p. 76; tradução nossa). 
A compreensão da profissão se constitui, segundo Kunstreich, no enfrentamento do conflito institucionalizado, isto é, no conflito entre as estruturas hegemônicas do sistema social em constante processo de reprodução e a exigência do direito dos(as) usuários(as) do Serviço Social a um lugar digno e justo na sociedade. É sempre também o conflito entre as posições distintas dos(as) assistentes sociais e dos(as) usuários(as) dentro do processo social de produção. Os sujeitos do exercício da profissão compreendem-se, portanto, como parte desse conflito entre adaptação e transformação, controle e emancipação. Por isso, Kunstreich constitui sua perspectiva de uma profissionalidade solidária que se consolida através da resistência dos(as) assistentes sociais à redução de seu exercício profissional ao papel de executores(as) na distribuição de censuras sociais. Essa profissionalidade solidária assume o conflito institucionalizado, aguenta as tensões decorrentes e se nega a transferi-lo unilateralmente aos(às) usuários(as).

Nesse sentido, o exercício da profissão orienta-se, segundo Kunstreich, na participação enquanto princípio fundamental de trabalho. Os diálogos prospectivos entre assistentes sociais e seus usuários(as) (AdressatInnen) formulam desafios concretos e possibilitam processos emancipatórios através da construção de relações sociais (Bildung des Sozialen) e da formação do sujeito pelas relações sociais em construção (Selbstbildung am Sozialen). Nesse contexto, Kunstreich descreve o agir profissional como "assistência" ao processo do(a) usuário(a) na construção de suas formas próprias de participação. Identificar a ação profissional como assistência não é nada óbvio levando em conta o contexto específico de uma reflexão alemã. Pois em alemão, os profissionais do Serviço Social não se denominam como assistentes sociais, mas como "trabalhadores sociais" (Sozialarbeiter: cf. também em inglês social work). Quando Kunstreich utiliza o termo "assistência", ele aponta para o protagonismo essencial do(a) usuário(a). O exercício da profissão pelo(a) assistente social - compreendido, segundo Kunstreich, como assistência — deve possibilitar ao sujeito social com o qual dialoga realizar novas opções de ação. Destarte, fortalece a estratégia de socialidades transversais enquanto tecidos de comunicação e de cooperação que conflitam com as institucionalidades hegemônicas.

Segundo Kunstreich, a distribuição injusta das diferentes formas de capital (econômico, social e cultural) é marca inerente de qualquer sociabilidade no capitalismo. Essa perspectiva tem implicações diretas na compreensão da relação entre teoria e prática. As questões analisadas pelas reflexões científicas do Serviço Social não se esgotam em seu horizonte teórico. Ao contrário, a construção teórica é parte de uma práxis social que engloba teoria e prática. Neste sentido, o desafio do Serviço Social não é apenas de "formular ações cientificamente fundamentadas, mas também de realizá-las enquanto agir concreto" (Kunstreich, 1994, p. 85; tradução nossa). 
Kunstreich supera o modelo clínico-normativo e propõe como referência para o exercício da profissão a análise do contexto real de vida do(a) usuário(a), o diálogo enquanto forma de construir objetivos comuns, a assistência como presença acompanhante na construção de trilhas emancipatórias e o foco central na ação protagônica. Esse modelo para o exercício da profissão renuncia a toda forma de diagnóstico em que a interpretação do profissional substitui a reflexão do(a) usuário(a) (stellvertretende Deutung). A referência, ao contrário, é a igualdade dos pontos de vista subjetivos que estabelece as condições da possibilidade de construir uma superação de situações-limites por meio da construção conjunta e participativa de perspectivas de ação (das gemeinsame Dritte als Aktion einer gemeinsam verantworteten Grenzüberschreitung) (Kunstreich, 2005, p. 364). Essa perspectiva participativa, sempre inserida no espaço social concreto (Sozialraum) prioriza o exercício da profissão no meio aberto e não em instituições fechadas. Assim mesmo, a ação profissional no meio aberto sempre ocorre em alguma forma de contexto institucional. Por isso, o mais importante para Kunstreich é a capacidade de as instituições se identificarem enquanto instituições apreendentes.

Quando Kunstreich fala dos(as) usuários(as) do Serviço Social, ele utiliza o termo Adressat/in e indica os(as) usuários(as) como aquelas pessoas às quais o Serviço Social se destina. ${ }^{1}$ Ele não identifica, no entanto, os(as) usuários(as) enquanto pessoas que demandam a compensação de déficits de socialização ou a adaptação ao contexto da reprodução da estrutura hegemônica da totalidade social. Ao contrário, o Serviço Social assume uma função de assistência ao fortalecimento de sujeitos individuais e coletivos que almejam afirmar seus direitos de cidadania e buscam superar a desigualdade social inerente a toda forma capitalista de organização social. Kunstreich identifica os sujeitos pensantes e ativos como ponto de partida de sua teoria crítica de Serviço Social. Esses sujeitos são sempre associados a possibilidades de participação em grupos formais e informais. "Essa rede de formas múltiplas de associação que busca a justiça social é, ao mesmo tempo, a arena e o conteúdo de uma pedagogia do social" (May, 2009, p. 96; tradução nossa).

Dessa forma, Kunstreich define o objeto de um Serviço Social crítico na "perspectiva de uma justiça igualitária" (Kunstreich, 2005, p. 1095; tradução nossa). Ele identifica o Serviço Social como elemento de uma pedagogia do social que fortalece através de sua dimensão maiêutica ${ }^{2}$ — enquanto assistência — as "formas múltiplas de associação em contextos solidários na luta por um lugar socialmente justo na sociedade" (Kunstreich, 1994, p. 94; tradução nossa).

1. O termo Adressat/in deriva da palavra Adresse (endereço). Portanto, indica aquele ao(à) qual a ação profissional se destina, isto é, o(a) destinatário(a).

2. Do grego "a arte de dar à luz", derivado de Sócrates. 
A delimitação dos(as) usuários(as) e do objeto do Serviço Social aponta para os valores centrais e os princípios éticos essenciais para Timm Kunstreich (2005, p. 1095; tradução nossa): "a suposição contrafática e normativa da igualdade de todos os sujeitos". "Isto significa afirmar em todos os seres humanos a qualidade de sujeitos [...]. Dentro dessa perspectiva não existe 'cobrança de ingresso' para a subjetividade humana" (Kunstreich, 1994, p. 97; tradução nossa). O Serviço Social é, portanto, uma contribuição à busca de fortalecer atores e processos sociais que resistem ao fato de serem "governados de tal maneira" (Michel Foucault).

\section{Conclusão}

O que chama a atenção nas reflexões de Timm Kunstreich não é apenas sua perspectiva crítico-materialista. Em seus textos, Kunstreich incorpora sistematicamente categorias referenciadas no pedagogo brasileiro Paulo Freire. Kunstreich "codifica" a realidade hegemônica e busca "decodificar" perspectivas emancipatórias. Ele trabalha o "diálogo" como referência central de uma teoria crítica de Serviço Social e aponta para perspectivas de superação de "situações-limites". Mas Kunstreich não faz apenas referência a categorias desenvolvidas por Paulo Freire. Ele cita explicitamente o "pedagogo dos oprimidos". Não existe um texto de Timm Kunstreich que não tenha uma ou mais referências bibliográficas de Paulo Freire.

Fiz o exercício inverso e procurei referências bibliográficas de Paulo Freire em obras representativas brasileiras de reflexão a respeito do Serviço Social. Depois de dez, quinze tentativas, abortei o exercício frustrado. Parece que, às vezes, é preciso ir longe para descobrir o que está por perto.

Certamente, a reflexão e a luta dos(as) assistentes sociais brasileiros(as) traça uma trajetória de enfrentamentos e de conquistas. $\mathrm{O}$ exemplo mais recente é a conquista de ver sancionada, no mês corrente, a lei federal que institui o Sistema Único de Assistência Social - Suas. Sem dúvida, cravar em lei uma luta histórica representa um passo importante. No entanto, a "cultura política de política social" (Sposati, 2004, p. 198) afirmada no texto da lei ainda está longe de ser hegemônica na sociedade brasileira e, inclusive, na prática dos(as) profissionais da assistência social. A transformação da letra legal em realidade efetiva, isto é, a "conquista do direito social[,] supõe um pacto entre sociedade - mercado - Estado sob a égide da universalização da cidadania" (Sposati, 2002, p. 41). E este pacto está longe de ser efetivado. Certamente, as reflexões de Paulo Freire poderiam contribuir para a efetivação na realidade concreta daquilo que já conquistou valor legal. Nesse sen- 
tido, penso que poderia valer a pena aprofundar as relações entre Paulo Freire e o Serviço Social: uma perspectiva para futuras reflexões.

De qualquer forma, faz bem saber da existência de ilhas que flutuam de forma contracorrente no mar hegemônico que continua a transformar o Serviço Social em instrumento da "arte de governar" (Michel Foucault).

Importa também perceber que as ilhas nunca flutuam. Nunca estão desconectadas da terra firme do planeta. Ilhas são pontos de resistência de uma realidade invisibilizada. Sobretudo em pleno contexto de aquecimento global que tende a elevar o nível do mar e nos leva a água hegemônica até o pescoço. No entanto, no interior do planta Terra há vida, há fogo que busca, continuamente, formas de ebulição. E esse fogo no centro da Terra alimenta-se da centralidade "da indignação com a violação da dignidade humana. [...] [Pois] a dignidade de todos(as) fundamenta a indivisibilidade do conjunto dos direitos humanos" (Habermas, 2010, p. 44-46; tradução nossa).

Recebido em 4/8/2011 - Aprovado em 31/8/2011

\section{Referências bibliográficas}

HABERMAS, J. Das utopische Gefälle: Blätter für deutsche und international Politik, Berlim, n. 8, p. 43-53, 2010.

IAMAMOTO, M. V. Serviço social em tempo de capital fetiche: capital financeiro, trabalho e questão social. 3. ed. São Paulo: Cortez, 2007.

JESSOP, B. Der Wohlfahrtsstaat im Übergang vom Fordismus zum Postfordismus. PROKLA —Zeitschrift für kritische Sozialwissenschaft, Berlim, v. 65, p. 4-33, 1986.

KOBEL, A. Kennzahlen zur Fallbelastung. Material didático para o Curso de Mestrado em Serviço Social. Bern, 2009.

KUNSTREICH, T. Ist kritische Soziale Arbeit möglich? Für eine Pädagogik des Sozialen. Widersprüche, Frankfurt a.M, n. 50, p. 85-100, 1994.

. Neo-Diagnostik — Modernisierung klinischer Professionalität? — Exposé für ein Methodenheft' der Widersprüche. Widersprüche, Frankfurt a.M, n. 88, p. 7-10, 2003.

Kritische Theorie - Historischer Materialismus. In: OTTO, H.-U.; THIERSCH, H. (Org.). Handbuch: Sozialarbeit/Sozialpädagogik. München und Basel: 3. Auflage, 2005. p. 1084-1097. 
KUNSTREICH, T. Markt macht Moral. zur moralischen Ökonomie der Sozialen Arbeit. Widersprüche, Frankfurt a.M, n. 99, p. 7-22, 2006.

; LINDENBERG, M. Die Tantalus-Situation. Soziale Arbeit mit Ausgegrenzten. In: THOLE, W. (Org.). Grundriss Soziale Arbeit. Ein einführendes Handbuch. Wiesbaden: 2. Überarbeitete und aktualisierte Auflage, 2005. p. 349-366.

; MAY, M. Soziale Arbeit als Bildung des Sozialen und Bildung am Sozialen. Widersprüche, Frankfurt a.M, n. 73, p. 35-52, 1999.

et al. Diagnose und/oder Dialog? Ein Briefwechsel. Widersprüche, Frankfurt a.M, n. 88, p. 11-31, 2003.

MAY, M. Aktuelle Theoriediskurse Sozialer Arbeit. Wiesbaden: VS Verlag für Sozialwissenschaften, 2., überarbeitete und erweiterte Auflage, 2008.

SOUSA SANTOS, B. Pela mão de Alice: o social e o político na pós-modernidade. 8. ed. Porto: Edições Afrontamento, 2002.

(Org.). A globalização e as ciências sociais. São Paulo: Cortez, 2005.

A gramática do tempo: para uma nova cultura política. São Paulo: Cortez, 2006.

SPOSATI, A. Regulação social tardia: características das políticas sociais latino-americanas na passagem entre o segundo e terceiro milênio. In: CADERNO IDEAÇÃO. Políticas sociais para um novo mundo necessário e possível. Porto Alegre, 2002. p. 33-53.

. Gestão intergovernamental para o enfrentamento da exclusão social no Brasil. In: WERTHEIN, J.; JOVCHELOVITCH NOLETO, M. (Org.). Pobreza e desigualdade no Brasil. Traçando caminhos para a inclusão social. Brasília: Organização das Nações Unidas para a Educação, a Ciência e a Cultura (Unesco), 2004. p. 177-198.

WEHRLE, B. From welfare to workfare: a modernização da hegemonia capitalista: análise da assistência social na Suíça, 2011. Dissertação (Mestrado em Serviço Social) — Pontifícia Universidade Católica, São Paulo. Anexo: Transcrição das entrevistas realizadas.

WYSS, K. Workfare: Sozialstaatliche Repression im Dienst des globalisierten Kapitalismus. Zürich: Edition 8, 2007. 